\title{
Education and clinical decision support for healthcare professionals on emergency preparedness for extremely dangerous pathogens: report of a conference workshop
}

\author{
Kieran Walsh, ${ }^{1}$ N Seyidov, ${ }^{2}$ M Wroczynski, ${ }^{3}$ G Payne, ${ }^{4}$ \\ L Bhagavatheeswaran $^{5}$
}

\begin{abstract}
Clinical decision support and e-learning will be essential if we are to achieve the goal of preventing outbreaks of infectious diseases caused by extremely dangerous pathogens. However, these resources on their own will not be enough to achieve this outcome. To achieve this outcome, resources must be integrated into undergraduate and postgraduate educational curricula, accredited as part of continuous professional development programmes, built around the knowledge and skills gaps of learners and developed using an evidencebased methodology that will enable healthcare professionals to put their learning into action for the benefit of both patients and populations. This article describes and contextualises the personal views discussed at a workshop on education and clinical decision support for healthcare professionals reacting to an infectious disease outbreak from extremely dangerous pathogens.
\end{abstract}

\section{INTRODUCTION}

Clinical decision support and e-learning for healthcare professionals will be essential if we are to achieve the goal of preventing outbreaks of infectious diseases caused by extremely dangerous pathogens. This article describes and contextualises the themes and personal views discussed at a workshop on education and clinical decision support for healthcare professionals reacting to an infectious disease outbreak from extremely dangerous pathogens.

\footnotetext{
'BMJ, BMA House, London, UK

${ }^{2}$ Department for Health Policy and Planning, Public Health and Reform Center, Ministry of Health, Baku, Azerbaijan

${ }^{3}$ Strategic Partnerships, Global Health and Global Health Security, BMJ, London, UK

${ }^{4}$ Global Health, BMJ, London, UK

${ }^{5}$ Global Health and Global Health Security, BMJ,

London, UK
}

Correspondence to Dr Kieran Walsh, BMJ, BMA House, London WC1H 9JR, UK; kmwalsh@bmj.com

\section{THE WORKSHOP}

The workshop was presented at the 2019 Biological Weapons Convention Meetings of Experts at the United Nations in Geneva on 7 August 2019. The purpose of the workshop was to seek the views of professionals from different sectors and different countries on e-learning and clinical decision support resources as means of educating healthcare professionals in extremely dangerous pathogens, building capacity and strengthening health systems. The workshop comprised 35 delegates with an interest in this subject. The delegates were from Europe, North America, the Middle East, Asia and the Caucasus. They represented different sectors including clinical medicine, infectious disease epidemiology, public and population health, laboratory medicine, military medicine and international diplomacy.

BMJ's resources in infectious diseases were discussed at the workshop. These include BMJ Learning_an online multimedia learning platform-and BMJ Best Practice-a clinical decision support tool. ${ }^{12}$ Both resources can be used to help doctors and other healthcare professionals to recognise, report and refer patients with serious infectious diseases. The purpose of the resources is 'capacity-building for detecting, reporting and responding to outbreaks of infectious disease'-'including in the areas of preparedness, response, and crisis management and mitigation' 3 Both resources have been made available to healthcare professionals, translated into relevant languages, accredited for the purposes of continuous professional development and integrated into relevant postgraduate curricula.

\section{THEMES}

Evidence-based response in the event of an outbreak of infectious disease

It can be difficult to mount an evidencebased response in the event of an outbreak of infectious disease caused by an extremely dangerous pathogen. There can be multiple challenges including sluggish health systems that do not respond quickly enough and the difficulties in getting healthcare professionals to think about these diseases when there are so many other priorities, and such a large volume of evidence that they have to keep up with. The evidence base is sometimes not helpful-because it is too academic and not practical, or too general and not applicable to individual situations, or too rigid and unable to be modified in light of population needs or patient preferences. The other difficulty is lack of resourcesmainly in logistics or personnel. Difficulties vary from country to country and also depending on the disease in question.

\section{Challenge of engaging doctors in} emergency preparedness

It can be a challenge to get doctors to learn about pandemic infectious diseases and so to build emergency preparedness. Such topics should be covered more in curricula-both undergraduate curricula in medical schools and postgraduate curricula in primary or secondary care training institutions. It is likely that national public health bodies could do more; however, it is also down to individual senior professionals to spend more time passing their knowledge and experience onto their juniors.

\section{Knowledge gaps of healthcare} professionals

There are considerable knowledge gaps among healthcare professionals in the field of dangerous infectious diseases. ${ }^{4}$ Lack of knowledge of extremely dangerous pathogens is serious as it could result in failure to recognise, report or refer affected patients. There is also a skills gap-for example, procedural skills in maintaining strict infection control and in donning and doffing personal protective equipment. This is in keeping with our own data from BMJ Learning which shows that healthcare professionals were only able to correctly answer one in three questions on the basics of personal protective equipment. The skills deficit is serious as it could result in healthcare professionals themselves becoming infected-with short-term and long-term implications for individuals and the healthcare system. Such professionals could also pass on infectious diseases-and they could be very dangerous spreaders-as they see lots of people who will be vulnerable to infection. 
Resources that healthcare professionals will need and use

Healthcare professionals need a variety of different types of resources on extremely dangerous pathogens. In some cases, the healthcare professional will know the diagnosis-for example, that a patient has anthrax and so will use clinical decision support to find the answer to specific questions on management or prognosis of anthrax. But sometimes the healthcare professional will not know the underlying diagnosis and so will need to enter clinical symptoms and signs into the resource and be confident that they will get an answer that they can rely on. BMJ Best Practice covers both use cases-where the diagnosis is known and not known. ${ }^{5}$ Features of the resources that healthcare professionals most appreciated included: the practical rather than academic focus of the resources; the accessibility of the resources-for example, on a desktop or a mobile app (both online and offline); and the amount of time needed for the healthcare professional to get an answer (ideally measured in seconds).

Bridging the gap between rhetoric and reality in emergency preparedness

There can be a considerable gap between rhetoric and reality in education on extremely dangerous pathogens and in how online education and clinical decision support resources can bridge that gap. For example, authorities might state the need for 'capacity-building for detecting, reporting and responding to outbreaks of infectious disease or biological weapons attacks' but this will be impossible without engaging front-line healthcare professionals. ${ }^{3}$ And the front-line healthcare professionals will only be engaged if the education on extremely dangerous pathogens fits within the framework of medical education in their country. In effect, this will mean learning resources that are accredited for the purpose of continuous professional development by the relevant regulatory authority in country. Similarly, although authorities agree on 'the need to promote interagency coordination and multisectoral cooperation to prepare for, detect and respond to infectious disease outbreaks whether natural, accidental or deliberate in nature', true cooperation and coordination will only be operationalised through partnerships with key stakeholders in countries that are most at risk. ${ }^{3}$ The sectors and agencies involved must include those from the medical education and healthcare improvement fields.

\section{CONCLUSIONS}

Clinical decision support and e-learning will be essential if we are to achieve the goal of preventing outbreaks of infectious diseases caused by extremely dangerous pathogens. However, these resources on their own will not be enough to achieve this outcome. Resources must be integrated into educational curricula, accredited as part of continuous professional development programmes, built around the knowledge gaps of learners and developed using an evidence-based methodology that will enable healthcare professionals to put their learning into action for the benefit of both patients and populations.

Acknowledgements We are grateful to all those who attended and contributed to the workshop.

Contributors KW wrote the first draft. All authors contributed to the design of the workshop and helped to interpret the outcomes of the workshop. All authors attended and contributed to the workshop. All authors revised the work critically for important intellectual content and approved the final version to be published.

Funding The authors have not declared a specific grant for this research from any funding agency in the public, commercial or not-for-profit sectors.

Competing interests KW works for BMJ Learning and BMJ Best Practice which produce a range of resources in infectious and non-infectious diseases.

Patient consent for publication Not required.

Provenance and peer review Not commissioned; internally peer reviewed.

(c) Author(s) (or their employer(s)) 2020. No commercial re-use. See rights and permissions. Published by BMJ.

D Check for updates

To cite Walsh K, Seyidov N, Wroczynski M, et al. BMJ Mil Health 2020;166:103-104.

Received 10 September 2019

Revised 26 October 2019

Accepted 3 November 2019

Published Online First 20 February 2020

BMJ Mil Health 2020;166:103-104.

doi:10.1136/jramc-2019-001328

\section{REFERENCES}

1 Kwag KH, González-Lorenzo M, Banzi R, et al. Providing doctors with high-quality information: an updated evaluation of web-based point-of-care information summaries. J Med Internet Res 2016;18:e15.

2 Walsh K, Sandars J, Kapoor SS, et al. Getting NICE guidelines into practice: can e-learning help? Clin Gov 2010;15:6-11.

3 Biological Weapons Convention. Article VII. Available: https://bwc1972.org/home/the-biological-weaponsconvention/article-vii/

4 Walsh K. E-Learning modules in new and emerging infectious diseases improve the applied knowledge and problem-solving skills of healthcare professional learners. Bmi Stel 2019:5:229-31.

5 Campbell JM, Umapathysivam K, Xue Y, et al. EvidenceBased practice point-of-care resources: a quantitative evaluation of quality, rigor, and content. Worldviews Evid Based Nurs 2015:12:313-27. 